\title{
Detailed experimental investigation of an all-active dual-order mode Mach-Zehnder wavelength converter
}

Wolfson, David; Fjelde, Tina; Kloch, Allan; Janz, C.; Poingt, F.; Guillemot, I.; Gaborit, F.; Renaud, M.

Published in:

Optical Fiber Communication Conference, 2000

Link to article, DOI:

10.1109/OFC.2000.868374

Publication date:

2000

Document Version

Publisher's PDF, also known as Version of record

Link back to DTU Orbit

Citation (APA):

Wolfson, D., Fjelde, T., Kloch, A., Janz, C., Poingt, F., Guillemot, I., Gaborit, F., \& Renaud, M. (2000). Detailed experimental investigation of an all-active dual-order mode Mach-Zehnder wavelength converter. In Optical Fiber Communication Conference, 2000 IEEE. https://doi.org/10.1109/OFC.2000.868374

\section{General rights}

Copyright and moral rights for the publications made accessible in the public portal are retained by the authors and/or other copyright owners and it is a condition of accessing publications that users recognise and abide by the legal requirements associated with these rights.

- Users may download and print one copy of any publication from the public portal for the purpose of private study or research.

- You may not further distribute the material or use it for any profit-making activity or commercial gain

- You may freely distribute the URL identifying the publication in the public portal 


\title{
Detailed experimental investigation of an all-active Dual- Order Mode Mach-Zehnder wavelength converter
}

\author{
D. Wolfson, T. Fjelde and A. Kloch \\ Research Center COM, Technical University of Denmark, Bldg. 349, DK-2800 Lyngby, Denmark \\ Telephone: +45 4525 3773, Fax: +45 4593 6581, e-mail: dw@com.dtu.dk \\ C. Janz, F. Poingt, I. Guillemot, F. Gaborit, and M. Renaud \\ OPTO+, Groupement d'Intérêt Economique \\ Route de Nozay, 91460 Marcoussis, France, Alcatel Corporate Research Center \\ Telephone: +33(0)16963 1561, Fax: +33(0)16963 1422, e-mail: Christopher.Janz@ms.alcatel.fr
}

\section{Introduction}

WDM networks will benefit from all-optical wavelength converters in order to increase the flexibility and capacity of the network. Consequently, the development of effective and practical wavelength converters has attracted considerable attention. The requirements of practical converters will be system dependent but nevertheless high-speed operation combined with the ability to convert over a wide wavelength range as well as to the same wavelength will be very important features. One of the most promising conversion techniques uses cross-phase modulation in semiconductor optical amplifiers (SOAs), where conversion at bit rates up to $40 \mathrm{Gbit} / \mathrm{s}$ has been reported in both Michelson and Mach-Zehnder interferometers [1,2]. However, conversion to the same wavelength is inherently not possible with a Michelson interferometer since the original signal and the converted signal are coupled out at the same output. Mach-Zehnder interferometers allow conversion to the same wavelength but only in a counter-directional propagation scheme, which is not attractive due to a limited speed potential as well as carrier redistribution effects causing jitter [3]. In a newly developed all-active dual-order mode (DOMO) Mach-Zehnder interferometer, conversion to the same wavelength is possible in a co-directional propagation scheme since the original input signal is suppressed in the device itself [4]. Furthermore, as the input signal is suppressed in the DOMO, filter-less operation is possible clearly a very important feature in cases, where a tuneable output wavelength is required.

Here, we assess the conversion capability of a DOMO Mach-Zehnder interferometer both for conversion to the same wavelength and different combinations of the signal and $\mathrm{CW}$ wavelength. The good performance in the entire EDFA window at $10 \mathrm{Gbit} / \mathrm{s}$ demonstrates that the DOMO converter is an attractive device for future all-optical wavelength conversion. Additionally, we demonstrate, for the first time, wavelength conversion at $20 \mathrm{Gbit} / \mathrm{s}$ with a high input signal suppression ratio.

\section{Device description and principle of operation}

As mentioned above, the big advantage of the DOMO compared to standard SOA-based interferometers is that the original signal is suppressed in the device allowing conversion to the same wavelength in the co-directional coupling scheme. This is achieved by using mode splitting/combining multi-mode interference (MMI) couplers at the input and output of the interferometer arms of the converter, as shown in Fig. 1 (a detailed description of the device and structure is given in [5]).

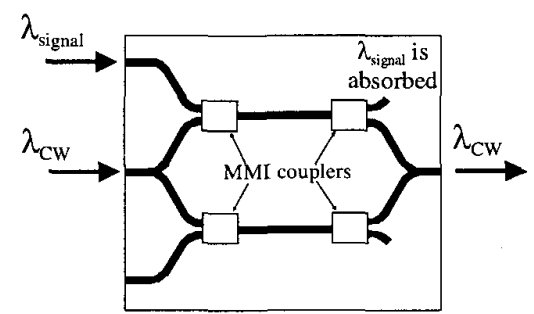

Fig. 1. Schematic of an all-active dual-order mode (DOMO) Mach-Zehnder converter incorporating MMI couplers at the input and output of the interferometer arms. The active waveguides in the interferometer arms are designed to sustain two lateral modes, whereas all other active waveguides are single-mode. 
The operation of the device is as follows: the input signal light is coupled (with $3 \mathrm{~dB}$ loss) into the first-order mode by the input MMI, while the CW light is losslessly coupled into the fundamental mode. After traversing the SOA in the interferometer arm, the signal and CW light is decoupled in the output MMI (identical to the input MMI). Consequently, the signal light is absorbed in an unpumped waveguide, whereas, the converted signal is guided to the output of the converter.

\section{Results and discussion}

The good performance of the DOMO converter at $10 \mathrm{Gbit} / \mathrm{s}$ is illustrated in Fig. 2 showing the converted eye diagram for conversion from $1545 \mathrm{~nm}$ to $1550 \mathrm{~nm}$ (Fig. 2.a) and the corresponding spectrum at the output of the DOMO measured in $0.1 \mathrm{~nm}$ (Fig. 2.b). As seen, a very clear and open eye diagram is obtained indicating potential for high-speed operation. The corresponding output spectrum, shown in Fig. 2.b, demonstrates an input signal suppression ratio (ISSR) and optical signal-to-noise ratio (OSNR) of $\sim 25 \mathrm{~dB}$ and $\sim 38 \mathrm{~dB}$, respectively.

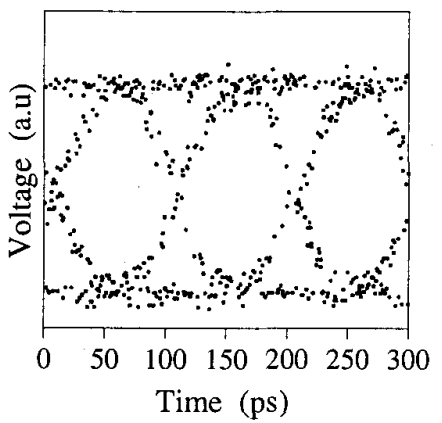

(a)

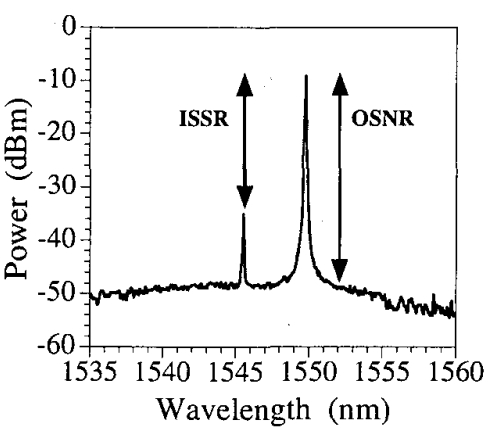

(b)

Fig. 2. (a): converted eye-diagram from $1545 \mathrm{~nm}$ to $1550 \mathrm{~nm}$ at $10 \mathrm{Gbi} / \mathrm{s}$. (b): corresponding spectrum at the output of the converter measured in $0.1 \mathrm{~nm}$ showing an input signal suppression ratio (ISSR) of $\sim 25 \mathrm{~dB}$ and an optical signal-to-noise ratio (OSNR) of $\sim 38 \mathrm{~dB}$.

Seen from a system perspective, it is very important that the all-optical wavelength converter is able to perform conversion for different signal and CW wavelengths, e.g., when used in a WDM cross-connect or as a wavelength adapter between different networks. But also conversion to the same wavelength can be required in several applications, a possibility the DOMO inherently is able to accommodate. The capability of the DOMO as a wavelength transparent device is demonstrated in Fig. 3. Fig. 3.a shows the pre-amplified penalty at $10 \mathrm{Gbit} / \mathrm{s}$ versus various combinations of the signal and $\mathrm{CW}$ wavelength, while Fig. 3.b shows the corresponding OSNR.

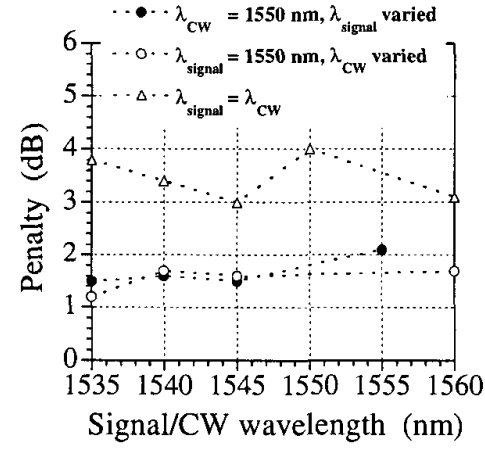

(a)

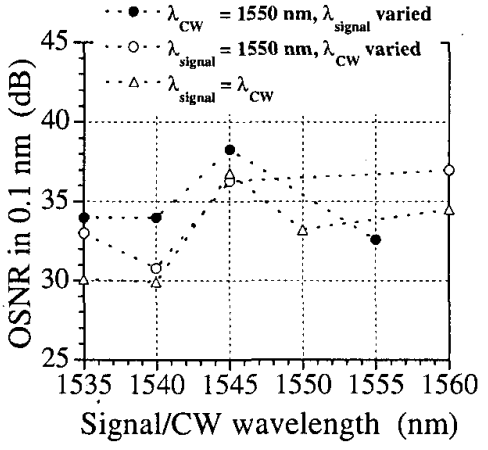

(b)

Fig. 3. (a): pre-amplified penalty versus various combinations of the signal and $\mathrm{CW}$ wavelengths, at $10 \mathrm{Gbit} / \mathrm{s}$. (b) : corresponding optical signal-to-noise ratio (OSNR). 


\section{4 / TuF3-3}

As demonstrated in Fig. 3.a, nearly wavelength-independent conversion is achieved in the case with unequal signal and $\mathrm{CW}$ wavelengths, with a resulting pre-amplified penalty between $\sim 1$ and $\sim 2 \mathrm{~dB}$. Note that the OSNR is above $30 \mathrm{~dB}$ in all cases. Furthermore, the measured ISSR values were typically $\sim 20$ $25 \mathrm{~dB}$. We emphasize that the bias currents to the device were kept constant in the measurements, and the only parameters adjusted were the optical input powers. Clearly, this is a very important feature for practical use of all-optical wavelength converters. As seen in Fig. 3.a, conversion to the same wavelength results in a pre-amplified penalty between $\sim 3$ and $\sim 4 \mathrm{~dB}$. The excess penalty of $\sim 2 \mathrm{~dB}$, as compared to conversion to different wavelengths, is explained by the ISSR values $(\sim 20-25 \mathrm{~dB})$, which are not quite high enough to ensure operation without degradation due to interferometric cross-talk when the input and output wavelengths are rigorously matched. We emphasize, however, that the observed excess penalty is nearly constant as a function of wavelength, indicating that the operation of the mode splitting/combining MMI couplers is essentially wavelength-independent in the range examined.

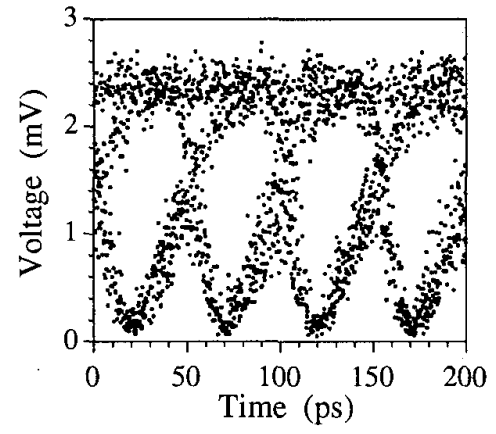

(a)

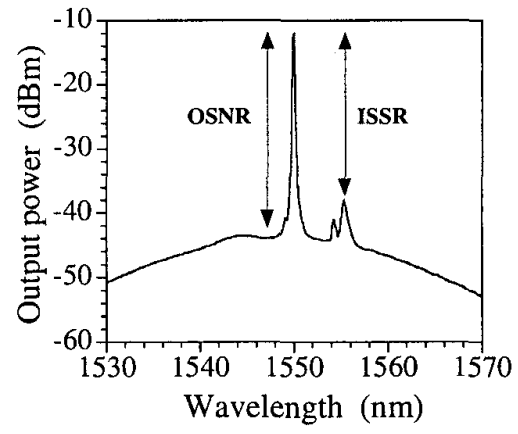

(b)

Fig. 4. (a): converted eye-diagram from $1555 \mathrm{~nm}$ to $1550 \mathrm{~nm}$ at $20 \mathrm{Gbit} / \mathrm{s}$ (RZ input signal format). (b): corresponding spectrum at the output of the converter measured in $0.1 \mathrm{~nm}$ showing an input signal suppression ratio (ISSR) of $\sim 27 \mathrm{~dB}$ and an optical signal-to-noise ratio (OSNR) of $\sim 30 \mathrm{~dB}$.

The high-speed potential of the DOMO Mach-Zehnder converter is illustrated in Fig. 4, showing the converted eye diagram (1555 to $1550 \mathrm{~nm}$ conversion) at $20 \mathrm{Gbit} / \mathrm{s}$ with an RZ input signal (Fig. 4.a) and the corresponding spectrum at the output of the converter (Fig. 4.b). As seen, a clear and open converted eye diagram is obtained, with an OSNR of $\sim 30 \mathrm{~dB}$ and an ISSR of $\sim 27 \mathrm{~dB}$, showing that a high ISSR indeed is possible even at bit rates well beyond $10 \mathrm{Gbit} / \mathrm{s}$.

\section{Summary}

The conversion capability of a new all-active DOMO Mach-Zehnder interferometer has been assessed experimentally at $10 \mathrm{Gbit} / \mathrm{s}$ in a co-directional propagation scheme. For signal and $\mathrm{CW}$ wavelengths covering the entire EDFA window the converter showed almost wavelength-independent performance, with a high signal-to-noise ratio of the converted signals. Additionally, conversion to the same wavelength, with nearly constant, low excess penalty, was achieved in the wavelength range 1535$1560 \mathrm{~nm}$. A clear and open eye diagram was also obtained at $20 \mathrm{Gbit} / \mathrm{s}$, together with a high input signal suppression ratio, demonstrating that the DOMO converter is an attractive device concept for all-optical wavelength conversion at high bit rates.

\section{References}

[1] C. Joergensen et al., In Technical Digest of OFC'97, paper TuO1, Dallas, USA, 1997.

[2] D. Wolfson et al., In Proc. of ECOC'99, paper WeB4,5, Nice, France, 1999.

[3] A. Kloch et al., In Technical Digest of OFC'99, paper FB4, San Diego, USA, 1999.

[4] C. Janz et al., In Proc. of ECOC'98, pp. 661-662, Madrid, Spain, 1998.

[5] C. Janz et al., In Proc. of ECOC'99, paper WeB4.6, Nice, France, 1999. 